\title{
Preparation and Properties of Two-Component and Double-Crosslinking Waterborne Polyurethane-Acrylic Dispersions
}

\author{
Nan Gao ${ }^{1,2}$, Zhuo Zhang ${ }^{2}$, Qingzhi Dong ${ }^{1}$ \\ ${ }^{1}$ East China University of Science and Technology, Shanghai, China \\ ${ }^{2}$ Shanghai Institute of Technology, Shanghai, China \\ Email: gaonanxf@sit.edu.cn
}

Received January 10, 2013; revised February 11, 2013; accepted February 20, 2013

Copyright (C) 2013 Nan Gao et al. This is an open access article distributed under the Creative Commons Attribution License, which permits unrestricted use, distribution, and reproduction in any medium, provided the original work is properly cited.

\begin{abstract}
In this paper, isophorone diisocyanate (IPDI), polyethylene glycol (PEG), dimethylolpropionic acid (DMPA) and internal crosslinking agent trimethylolpropane (TMP) were used to prepare waterborne polyurethane. And then double-crosslinked polyurethane-acrylic composite aqueous dispersion was prepared in which polyacrylate was adopted to modify waterborne polyurethane and some special external crosslinking agents were added including silicone and trifunctional aziridine. The influence of the amounts of internal and external crosslinking agents, emulsifier, initiator on the particle size, particle size distribution, viscosity, molecular weight, as well as water adsorption ratio were studied.
\end{abstract}

Keywords: Waterborne Polyurethane-Acrylic Dispersions; Two-Component; Double-Crosslinking

\section{Introduction}

Polyurethane-acrylate (PUA) waterborne dispersion, with its advantages of excellent weather resistance, pigment affinity, cost-effectiveness over PU emulsion, has been an important research focus. But, to some extent, the application of PUA is limited by its poor chemical resistance, poor mechanical properties and poor water resistance, etc. [1-4]. In recent years, much relative research has been conducted to study how to enhance their properties [5-9], but little has been reported to discuss the effect of synthesis parameters on the properties of PUA in detail. This study was designed to enhance the water resistance of PUA by adding trifunctional polyols and some special external crosslinking agents such as silicone and trifunctional aziridine so as to improve its water resistance. Then the prepared water-resistance PUA emulsion can be used as the film-forming resin in coatings and adhesive.

\section{Experiment}

\subsection{Materials}

1) Polyethylene glycol (PEG) 1000 (provided by Shanghai resin factory);

2) Dimethylolpropionic acid (DMPA), trimethylolpro- pane (TMP) and trifunctional aziridine (QL-1000-Ga) are all CP-grade;

3) Isophorone diisocyanate (IPDI) (provided by BASF);

4) 2-Hydroxyethyl acrylate (HEA), triethylamine (TEA), sodium dodecyl sulfate (SDS), Tween-60, methyl methacrylate (MMA), butyl acrylate (BA), potassium persulfate (KPS);

5) 1-Methyl-2-pyrrolidinone (NMP), ethanol (EtOH) and external crosslinking agents are all AR-grade.

\subsection{Experimental Process}

\section{Step1: Preparation of PU prepolymer}

The PEG 1000 was introduced into a three-necked vessel with reflux condenser, stirrer and thermometer, then heated to $100^{\circ} \mathrm{C}$ and dehydrated under vacuum for 1 $\mathrm{h}$. Then the vessel was cooled to $80^{\circ} \mathrm{C}$ and dehydrated for about $0.5 \mathrm{~h}$ after the DMPA and TMP being added into the reactor. Subsequently, the reactor was cooled again to about $70^{\circ} \mathrm{C}$ for the dropping of IPDI with high-speed stirring. When the dropping of IPDI was finished, the mixture was heated up to $80^{\circ} \mathrm{C}$ to react for $3 \mathrm{~h}$ (some solvent was added), and then cooled to $60^{\circ} \mathrm{C}$ for adding HEA. After reacting for $1.5-2 \mathrm{~h}$, the prepolymer was neutralized with TEA for approximately $0.5 \mathrm{~h}$. Finally, the vessel was cooled to $20^{\circ} \mathrm{C}-30^{\circ} \mathrm{C}$, followed by dropping 
ice water with stirring to obtain the PU dispersion.

\section{Step2: Preparation of PUA}

The obtained preploymer was introduced into a threenecked vessel, dispersed with deionized water followed by adding SDS and TWEEN, stirred and emulsified at $50^{\circ} \mathrm{C}$. And then, the monomer mixture (MMA/BA) and the initiator (KPS) aqueous solution were added. After reacting at $70^{\circ} \mathrm{C}$ for about $3 \mathrm{~h}$, the system was cooled to $50^{\circ} \mathrm{C}-60^{\circ} \mathrm{C}$. TEA was added to keep the $\mathrm{pH}$ value within $8-8.5$.
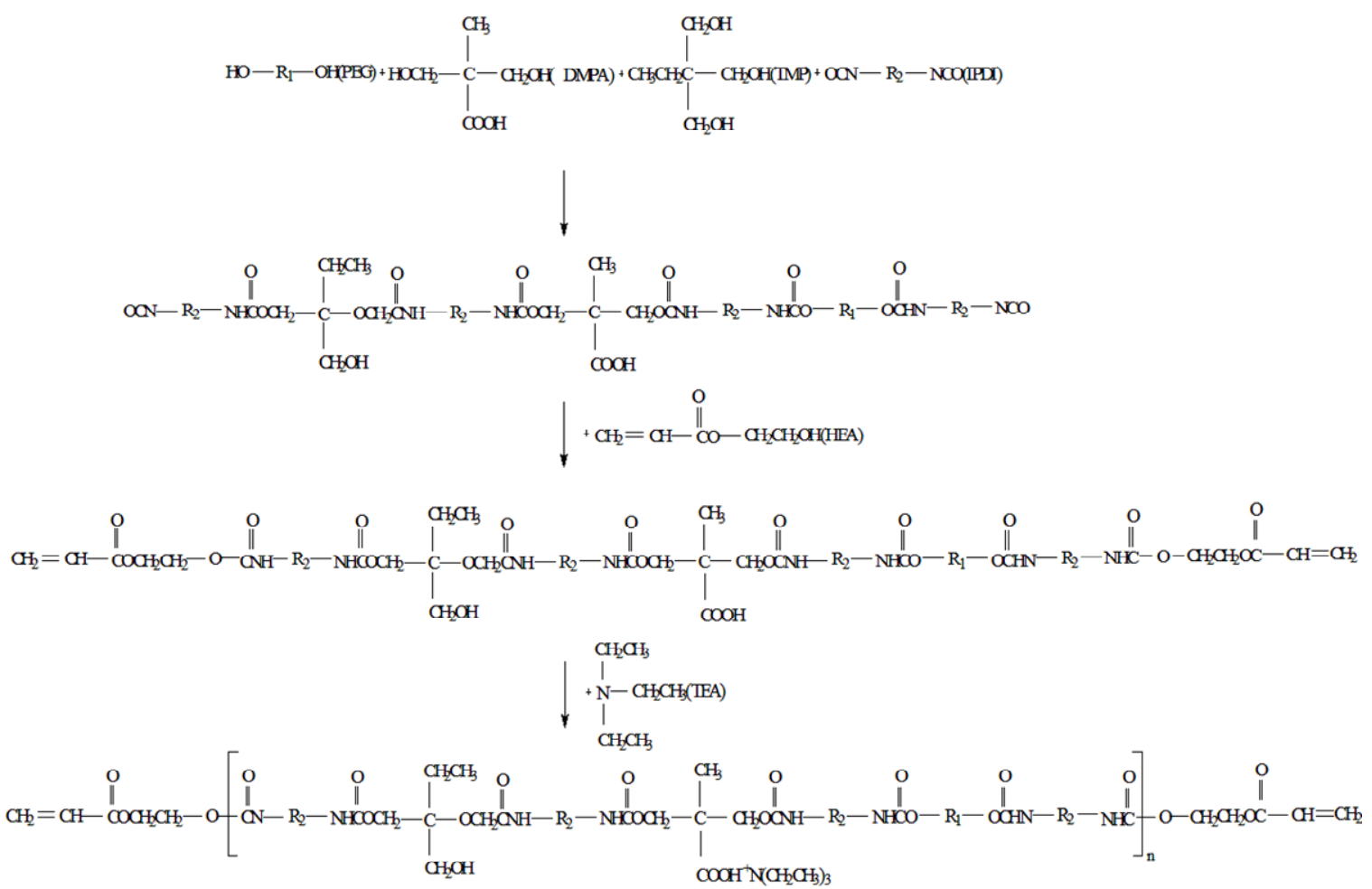

Scheme 1. Preparation process of PU prepolymer.

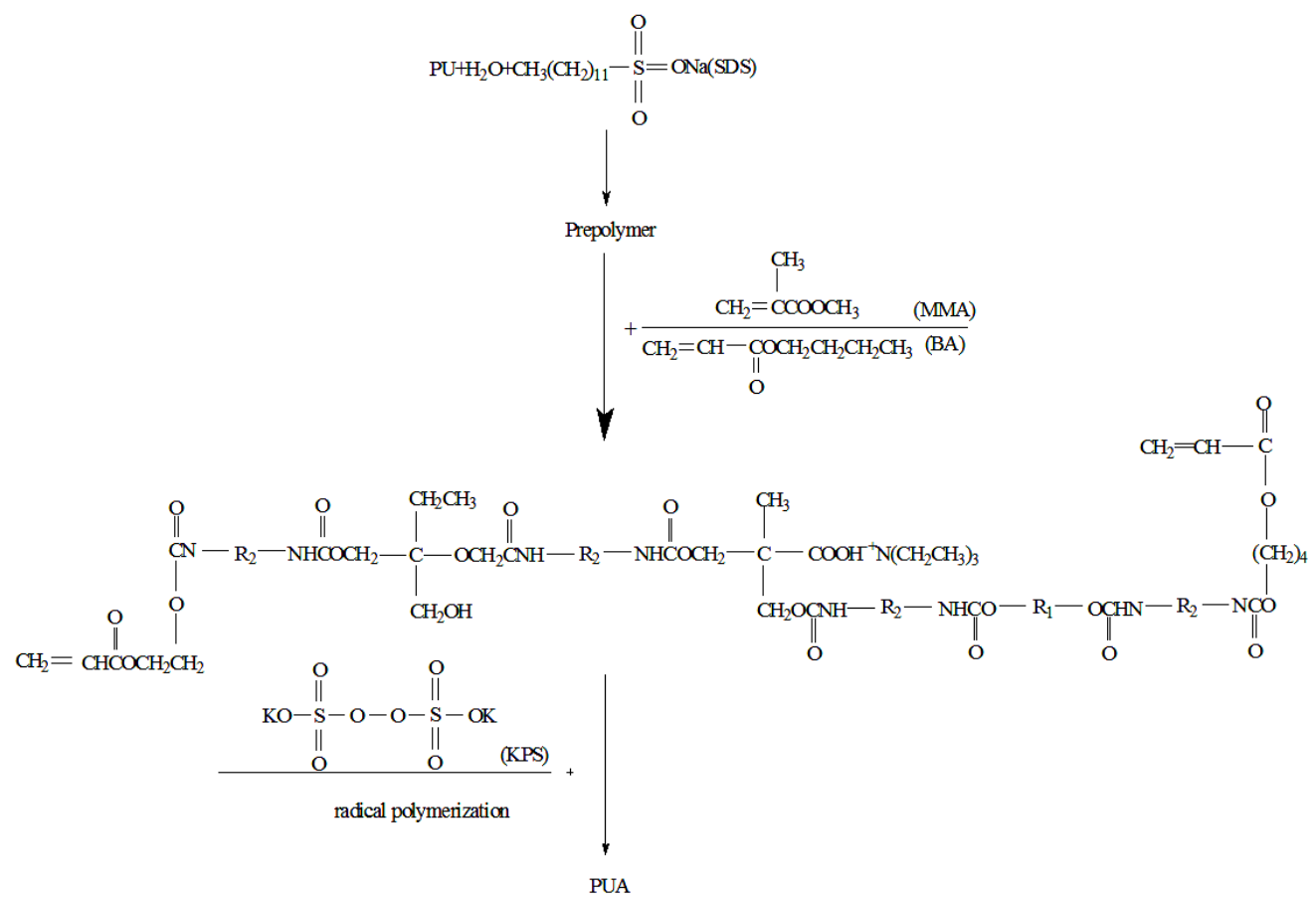

Scheme 2. Preparation process of PUA. 


\subsection{Characterization}

Solid content (C \%)

$$
\mathrm{C} \%=\left(\mathrm{M}_{3}-\mathrm{M}_{1}\right) \times 100 /\left(\mathrm{M}_{2}-\mathrm{M}_{1}\right)
$$

in which

$\mathrm{M}_{1}$ - the original weight of a small glass cup.

$\mathrm{M}_{2}$ - the gross weight of the cup and sample (taking from the obtained dispersion).

$\mathrm{M}_{3}$ - the gross weight of the cup and sample after being placed in an oven at $60^{\circ} \mathrm{C}$ for $24 \mathrm{~h}$.

\section{Particle size and particle size distribution}

The particle size and its distribution of the obtained dispersion were measured by a LS 230 laser particle sizer produced by British MALVEN Company and the measuring range was $0.02 \mu \mathrm{m}-2 \mathrm{~mm}$.

\section{Stability}

The samples were placed in TL-5.0W type centrifuge for the measurement of stability.

\section{Water absorption}

Water absorption $(\%)=\left(\mathrm{Mn}_{3}-\mathrm{Mn}_{2}\right) \times 100 /\left(\mathrm{Mn}_{2}-\right.$ $\left.\mathrm{Mn}_{1}\right)$.

in which

$\mathrm{Mn}_{1}$ - the original weight of each slide.

$\mathrm{Mn}_{2}$ - the weight of slide (dropped with obtained dispersion) after being placed in an oven at $60{ }^{\circ} \mathrm{C}$ for $24 \mathrm{~h}$.

$\mathrm{Mn}_{3}$ - the weight of slide after being immersed in water for $24 \mathrm{~h}$ (removed using dry filter paper).

Viscosity

The viscosity of the samples was measured with DNJ9S.

IR

FTIR spectra were obtained with NEXUS2870 type device of U.S. NICOLET Company.

\section{Results and Discussion}

\subsection{Effect of Internal Crosslinking Agent on the Properties of PU}

Figure 1 shows the effect of different amount of internal crosslinking agent (TMP) on the viscosity of PU dispersions and water absorption of PU films. The results indicate that the viscosity of PU dispersion increases significantly with the increase of TMP $(2 \%-6 \%)$. The reason may be that a certain degree of crosslinking structure was formed with the addition of trifunctional TMP; but as the TMP content $(6 \%-10 \%)$ increases further, the viscosity begins to fall instead of rising, which seems contradictory to the crosslinking mechanisms. This was mainly because that the crosslinking points became too dense as the TMP content increased from $6 \%$ to $10 \%$, which made the dispersion of PU in water difficult. So the observed viscosity reduction might be due to the uneven dispersion, which was also proved by the corresponding water absorption of the PU film as shown in Figure 1. Simultaneously, the crosslinking increased the difficulty of experimental operation. Gelation was likely to form as the amount of TMP increased, leading to much trouble with the following modification by acrylic monomers. This phenomena and results are not consistant with the primary relative research report [1,5]. So, in this case, excessive crosslinking in the polyurethane network is not preferred.

\subsection{Effect of Emulsifiers on the Properties of PUA Dispersions}

Table 1 shows the influence of different emulsifiers on the properties of PUA emulsions. From the perspective of the appearance, emulsions changed slightly from the white, milk white with blue light, milk white without blue light to white. This could be due to that, at the beginning, the number of latex particles increased while the particle size reduced; but as the emulsifier increases further, the particle size of aqueous emulsion becomed larger. The stability tests indicated that the use of single anionic emulsifier, SDS or nonionic Tween, could not

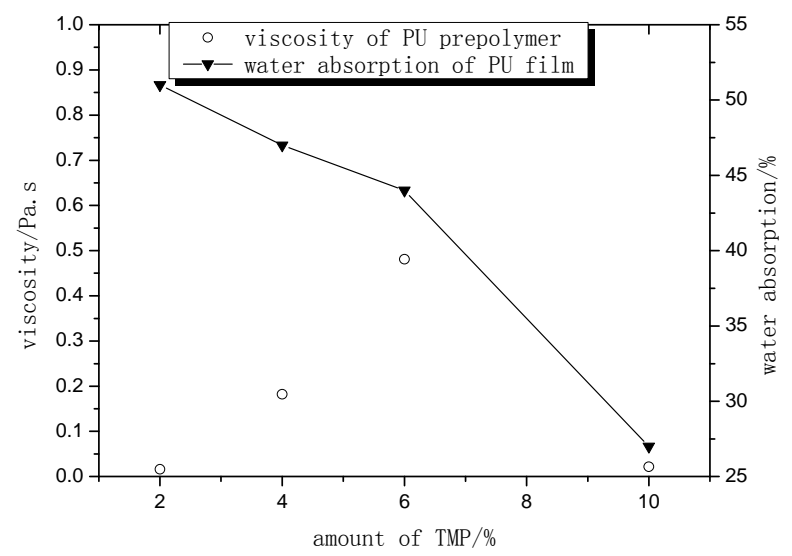

Figure 1. Internal crosslinking agent amount vs. viscosity of PU prepolymer and water absorption of PU film.

Table 1. Effect of emulsifier type and amount on the properties of PUA dispersions.

\begin{tabular}{|c|c|c|c|}
\hline $\begin{array}{c}\begin{array}{c}\text { Amount } \\
\text { of } \\
\text { emulsifier } \\
(\%)\end{array} \\
\end{array}$ & Emulsifier type & Appearance & Stability \\
\hline 0.6 & SDS & White & Delamination \\
\hline 0.6 & Tween-60 & White & Delamination \\
\hline 0.7 & $\begin{array}{c}\text { SDS + } \\
\text { Tween-60 }\end{array}$ & White & \\
\hline 1.4 & $\begin{array}{c}\text { SDS + } \\
\text { Tween-60 }\end{array}$ & $\begin{array}{l}\text { Milk white, } \\
\text { blue light }\end{array}$ & \\
\hline 2.1 & $\begin{array}{c}\text { SDS + } \\
\text { Tween-60 }\end{array}$ & $\begin{array}{c}\text { Milk white, } \\
\text { without } \\
\text { blue light }\end{array}$ & $\begin{array}{c}\text { Without } \\
\text { apparent } \\
\text { delamination }\end{array}$ \\
\hline 2.8 & $\begin{array}{c}\text { SDS + } \\
\text { Tween-60 }\end{array}$ & White & \\
\hline 3.5 & $\begin{array}{c}\text { SDS + } \\
\text { Tween-60 }\end{array}$ & White & \\
\hline
\end{tabular}


produce stable aqueous dispersion without delamiation, unless the composite emulsifier was adopted. Generally, the particle size was not strictly proportional to the amount of the composite emulsifier.

Figure 2 shows the effect of the emulsifier amount on the viscosity of PUA dispersions and the water absorption of PUA films. The water absorption increased alongwith the increase of the emulsifier amount. This was because that the anionic emulsifier SDS contains sulfonate, whose existence directly affected the water resistance of the films. Thus the water resistance of film reduced with the increase of the emulsifier amount, especially in the case of the anionic emulsifier. So the amount of emulsifier in the emulsions should be kept in a proper scale. And also from Figure 1, viscosity of PUA emulsions remained unchanged alongwith the increase of emulsifier, showing that the concentration of composite emulsifier nearly had no effect on the viscosity of PUA dispersions.

\subsection{Effect of the Emulsifier Amount on the Particle Size and Particle Size Distribution of PUA Dispersions}

Figure 3 shows the relationship between the emulsifier amount and the particle size and its distribution. The resulting latex particles became smaller with the increase of emulsifier $(0.74 \%-1.4 \%)$. The reason for this change could be that the composite emulsifier improved the function of three-dimensional spaces resistance or electrostatic repulsion on the surface of latex particle, which prevented the coalescence between the dispersed particles and made the particle size small and stable, as corroborated from the data in Table 1. But with the further increase of the amount of emulsifier $(1.4 \%-2.8 \%)$, the resulting particles size become lager, from this point, the function mechanism of anionic emulsifier was different from that of the ordinary emulsion polymerization. This might be due to that the polymerization in the research

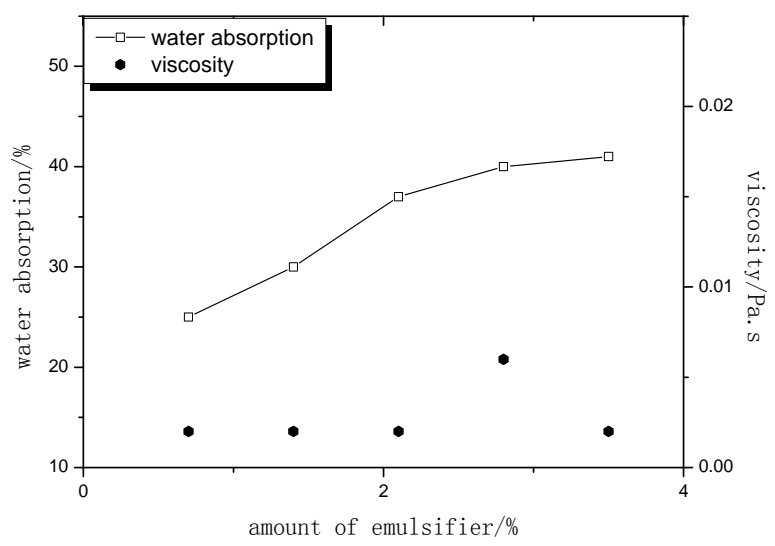

Figure 2. Concentration of composite emulsifier (SDS + Tween) vs. water absorption and viscosity.

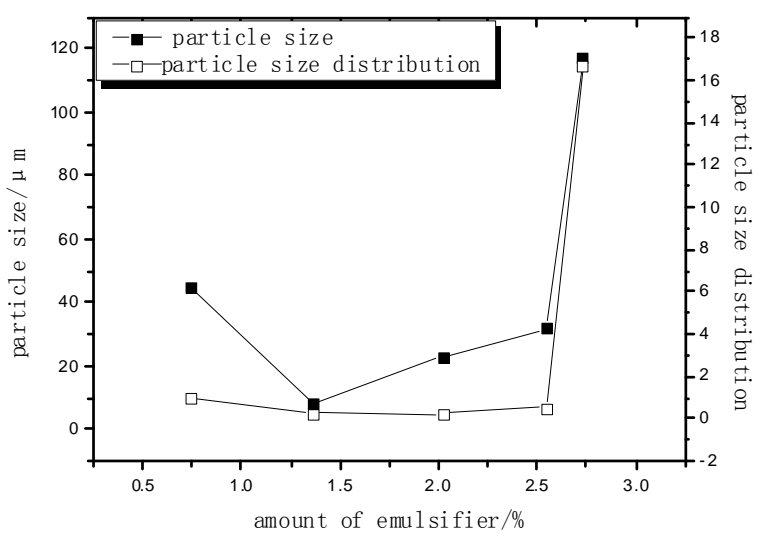

Figure 3. Concentration of emulsifier vs. particle size and particle size distribution.

system included simultaneously the homopolymerization and copolymerization of acrylic monomers based on the PU seed emulsion, which was different from the general emulsion polymerization. Too much anionic emulsifier might not be conducive to the emulsion stability of PU emulsions.

The particle size distribution becomes narrow with the increase of the amount of emulsifier $(0.7 \%-2.1 \%)$. But with the further increase of emulsifier $(2.1 \%-2.8 \%)$, the particle size distribution became wider, which was mainly caused by the increase of the fraction of micelles nucleation or homogeneous nucleation with excessive emulsifier.

\subsection{Effect of Initiator Concentration on the Molecular Weight of Non-Crosslinked PUA and Secondary Nucleation Homopolymer}

The molecular weight and molecular weight distribution of PUA dispersions could not be measured accurately because of the addition of internal crosslinking agent. But the GPC measurement data could indicate the molecular weight and molecular weight distribution of polymers dissolved in THF (mobile phase in GPC). Noncrosslinked PUA and acrylate homopolymer (sec- ondary nucleation) could be studied by GPC curves.

Figure 4 shows the GPC curve of PUA dispersions under the condition that the initiator concentration equaled $0.22 \%$. GPC curve occur two distinct eluting peaks instead of a single peak, namely, a weak largemolecular-weight polymer $\left(\mathrm{M}_{\mathrm{w} 1}\right)$ peak and a strong lowmolecular-weight polymer $\left(\mathrm{M}_{\mathrm{w} 2}\right)$ peak. Polymer $\left(\mathrm{M}_{\mathrm{w} 1}\right)$ might be due to the copolymerization of acrylic monomers with prepolymer (non-crosslinked) and polymer $\left(\mathrm{M}_{\mathrm{w} 2}\right)$ might be the homo-polymerization of acrylic monomers. These two reactions were competitive during the preparation of waterborne PUA composite dispersions.

Figure 5 shows the effect of different initiator concen- 


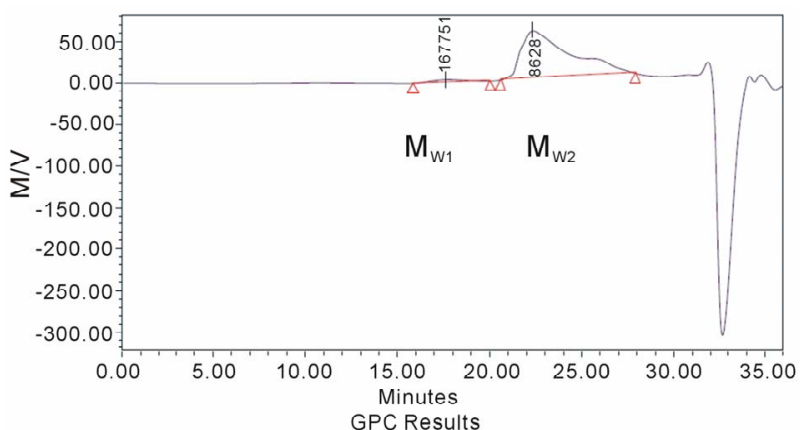

Figure 4. GPC curve of PUA dispersion (soluble).

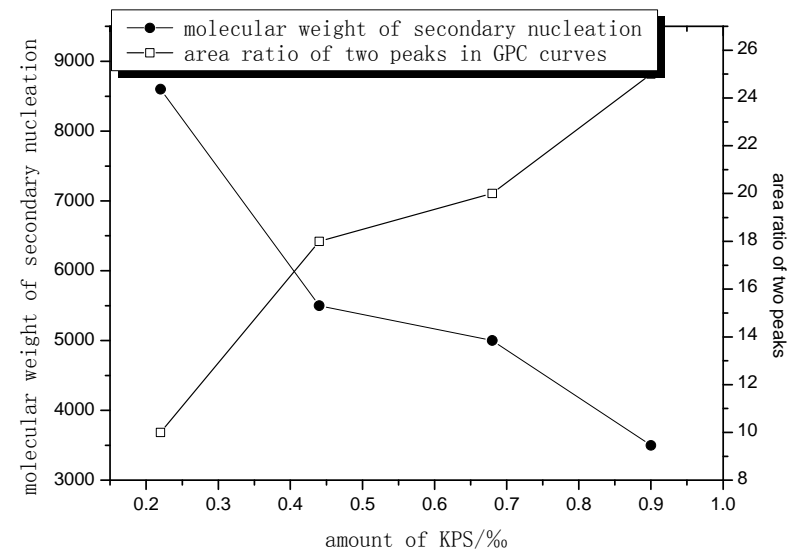

Figure 5. Concentration of initiator vs. molecular weight $\left(\mathrm{M}_{\mathrm{w} 2}\right)$ and ratio of second nucleation.

tration on the molecular weight and peak area ratio of two polymers. It could be seen from Figure 5, the molecular weight $\left(\mathrm{M}_{\mathrm{w} 2}\right)$ decreased overall alongwith the increase of initiator concentration, but the area fraction increased as compared with that of the high-molecularweight polymer. It might be due to that the increase of initiator concentration led to more active centers, thus accelerating the reaction rate of secondary nucleation, and making the molecular weight $\left(\mathrm{M}_{\mathrm{w} 2}\right)$ decrease. Simultaneously, the fractions of secondary nucleation increased due to the area fraction presented in Figure 5. So, the increase of initiator concentration could accelerate the secondary reaction and bring about diverse effect on the modification of PU dispersions.

\subsection{Effect of Initiator Concentration on the Particle Size and Particle Size Distribution of PUA}

Figure 6 shows the effect of initiator concentration on the particle size and particle size distribution of PUA aqueous dispersions. It could be seen that the average size and size distribution generally increased as the initiator content increases, but the growth extent was not significant. So it can be concluded that the amount of initiator has little effect on the particle size and particle size distribution of PUA emulsions. The minute change might be due to that the ions in the PUA emulsions increased with the increase of the amount of initiator, which would, to some extent, affect the stability of the PUA emulsions and make the observed particle size grow.

Particles in the aqueous emulsion were finely distributed, and the average particle size was $20.07 \mu \mathrm{m}$ (Figure 7).

\subsection{Effect of Solid Content of the PUA Dispersions}

Figure 8 shows the effect of different solid content on the particle size and its distribution of the PUA emulsions. It could be seen from Figure 8, with the increase of solid content, the average particle size increased accordingly. It is known that the amount of monomer within the system increases with the increase of solid content. And the particle size in the aqueous emulsion become larger through the motion collision because the particle surface did not form a thick layer of steric hindrance or double shells when the emulsifier amount keeps constant. Furthermore, if the steric layer was too thin, or the electric double layer was not thick enough, the particles in the emulsion might be coagulated.

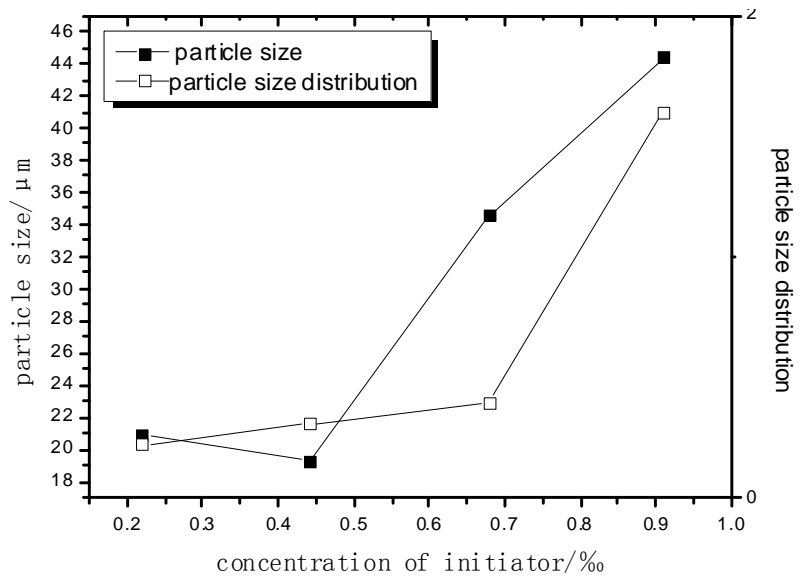

Figure 6. Concentration of initiator vs. particle size and particle size distribution

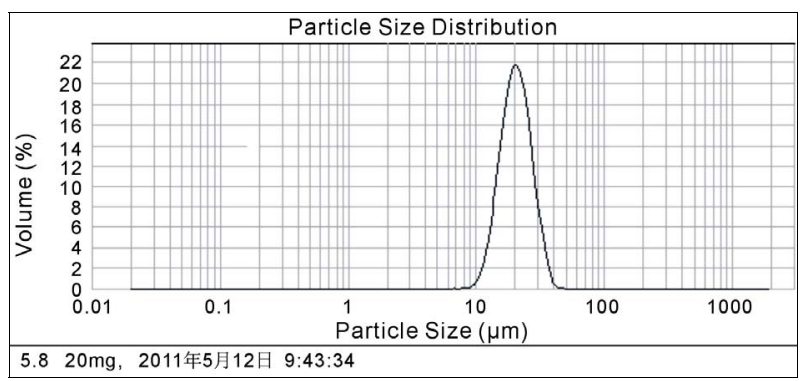

Figure 7. Particle size distribution curve (condition: concentration of initiator $\mathbf{= 0 . 2 2 \%}$ ) . 


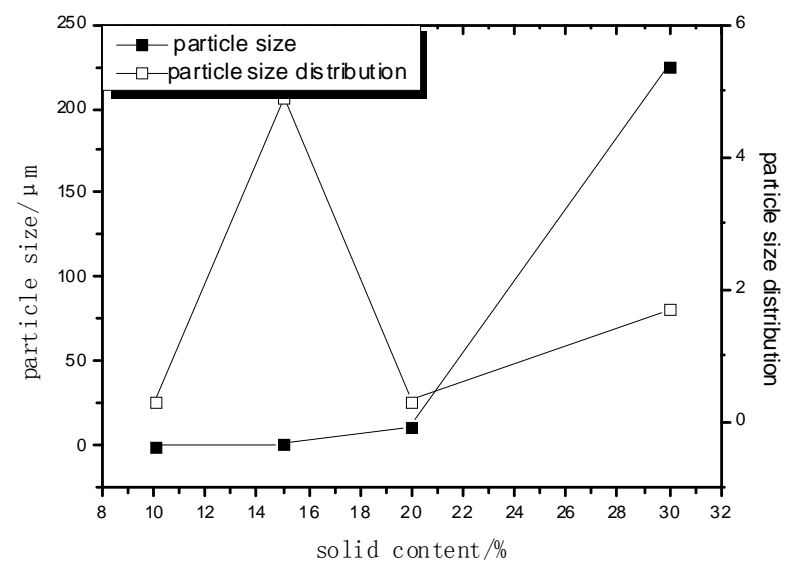

Figure 8. Solid content vs. particle size and particle size distribution.

\subsection{Analysis of the Structure of PUA Dispersions}

Figure 9 shows that the absorption peaks at $2270 \mathrm{~cm}^{-1}$ (-NCO) and $3530 \mathrm{~cm}^{-1}(\mathrm{O}-\mathrm{H})$ disappeared after synthetic reaction, and a strong and wide stretching vibration absorption peak at $3327 \mathrm{~cm}^{-1}$ appeared which was due to the stretching vibration of $\mathrm{N}-\mathrm{H}$ and a small part of free water. Simultaneously, the absorption peak at $1718 \mathrm{~cm}^{-1}$ was apparently due to the urethane linkages in products. The bending vibration peak at $1640-1680 \mathrm{~cm}^{-1}$ and the stretching vibration peak at $1248 \mathrm{~cm}^{-1}$ represented the structure of $\mathrm{C}=\mathrm{O}$ and $\mathrm{C}-\mathrm{N}$, respectively. Also a characteristic absorption peak of BA at $953 \mathrm{~cm}^{-1}$ occurred.

\subsection{External Crosslinking Agents}

\subsubsection{External Crosslinking Agent 1 (Silicone)}

As can be seen from Figure 10, water resistance can be improved by adding 0 to $2 \%$ of the external crosslinking agent 1 (silicone). However, the dosage of silicone greater than $2 \%$ induced undesirable influence on the water resistance, possibly because that silicone not only has low surface free energy and high flexibility, but also is incompatible with most of organic polymers.

\subsubsection{External Crosslinking Agent 2 (Trifunctional Aziridine)}

As can be seen from Figure 11, with the increase of the amount of external crosslinking agent 2 (trifunctional arizidine), the water absorption of PUA film reduced. This was mainly due to that the aziridine crosslinker, as a latent curing agent, could react with carboxyl and hydroxyl group as the $\mathrm{pH}$ value decreased during the PUA film-forming process. Accordingly, the content of hydrophilic groups including the carboxyl and hydroxyl groups was reduced. So the crosslinked network structure decreased the water absorption and improved the water resistance.

\section{Conclusions}

1) The emulsifiers had little influence on the viscosity of the PUA emulsion, but they would increase the water absorption and lower the water resistance of the PUA

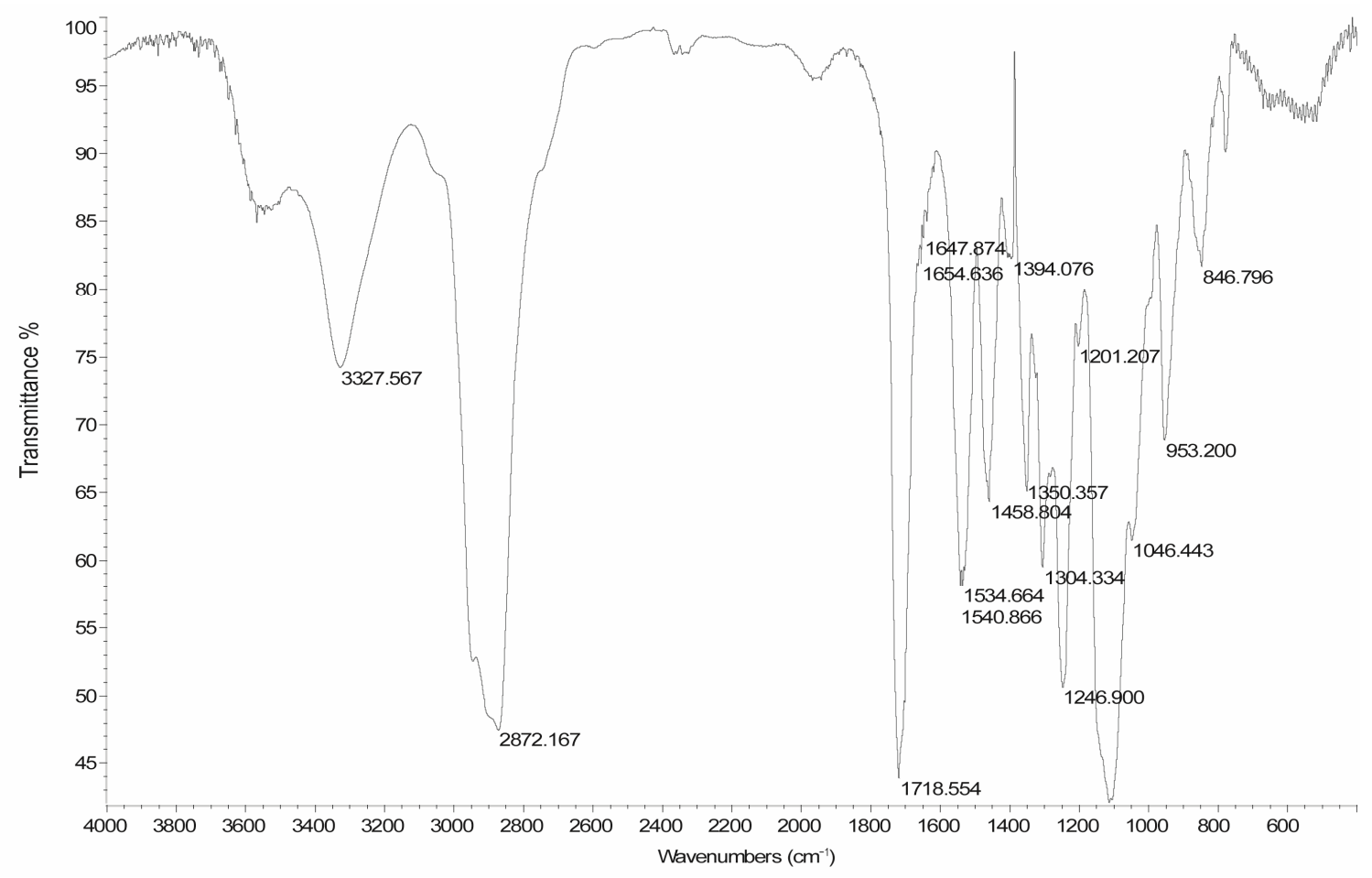

Figure 9. IR spectra of PUA emulsion. 


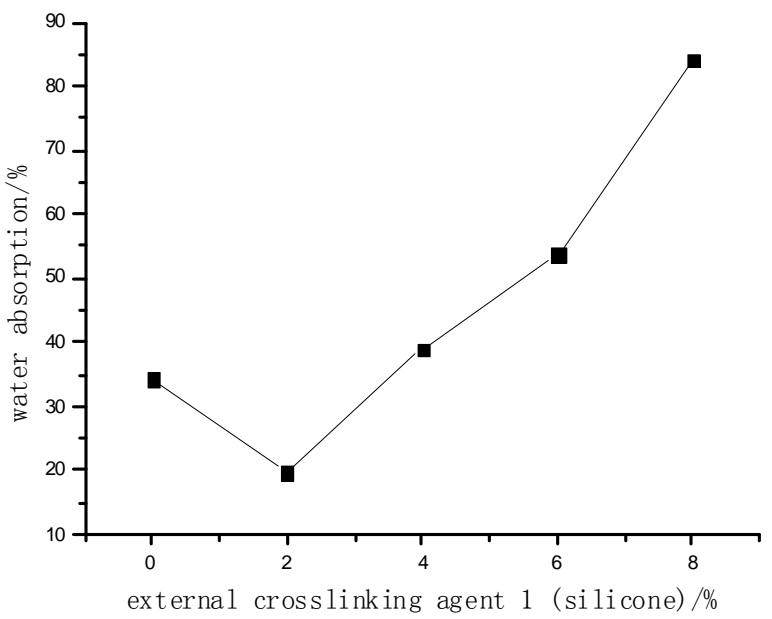

Figure 10. External crosslinking agent 1 (silicone) vs. water absorption.

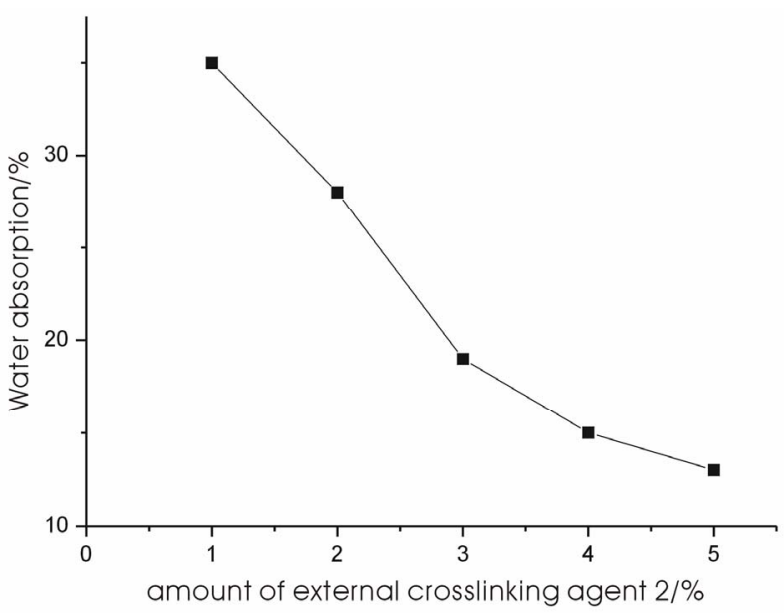

Figure 11. External crosslinking agent 2 (trifunctional aziridine) vs. water absorption.

film. The composite emulsifier, instead of single emulsifier, was required to provide enough stabilization to the emulsions.

2) The increase of initiator amount could lead to the increase of the particle size and its distribution of the PUA emulsion, but reduce the molecular weight of the PUA.

3) The improvement of water resistance by the addi- tion of silicone external crosslinking agent was limited, while the aziridine external crosslinking agent could have positive effect on the water resistance of PUA film. However, the addition of small amount $(<2 \%)$ of silicone could provide PUA with better water resistance than aziridine.

\section{REFERENCES}

[1] W. S. Wang, C. Y. Pan and J. Ceng, "Synthesis of Cross Linking Aqueous Polyurethane," Acta Polymerica Sinica, No. 3, 2000, pp. 319-324.

[2] H. Peng, G. F. Huang and Q. Lu, "Kinetics and Nucleation Mechanism of Silicone Emulsion," Journal of Functional Polymers, Vol. 13, No. 2, 2000, pp. 173-176.

[3] F. Ling, "Single-Component and Self-Crosslinking Aqueous Emulsion Polyurethane Coating," Application of Chemical Industry, Vol. 30, No. 2, 2001, pp. 29-31.

[4] F. A. Yan, "Development of Two-Component Waterborne Polyurethane Coatings," Coatings Industry, Vol. 33, No. 5, 2003, pp. 37-39.

[5] P. Chen and J. M. Liu, "Effects of Cross Linking Agent on the Performance of Two-Component Waterborne Polyurethane Coating," Coating Industry, Vol. 33, No. 5, 2003, pp. 9-11.

[6] J. Q. Qu, P. Wei and H. Q. Chen, "Synthesis and Characterization of Two-Component Waterborne Polyurethane," School of Chemical Engineering Journal, Vol. 16, No. 2, 2002, pp. 212-216.

[7] C. H. Liu and Z. Q. Fang, "Preliminary Study for Waterborne Polyurethane-Acrylate Modified by Epoxy Resin," Polyurethane Industry, Vol. 15, No. 3, 2002, p. 23.

[8] H. Kim, J. S. Shin and I. W. Cheong, "Seeded Emulsion Polymerization of Methyl Methacrylate Using Aqueous Polyurethane Dispersion: Effect of Hard Segment on Grafting Efficiency," Colloids and Surfaces A, Vol. 207, No. 1-3, 2002, pp. 169-176. doi:10.1016/S0927-7757(02)00092-4

[9] U. Sebenik, "Seeded Semibatch Emulsion Copolymerzation of Methyl Methacrylate and Butyl Acrylate Using Polyurethane Dispersion: Effect of Soft Segment Length on Kinetics," Colloids and Surfaces A, Vol. 233, No. 1-3, 2004, pp. 51-62. doi:10.1016/j.colsurfa.2003.11.021 